\title{
Analysis of Thin Walled Wavy Shell of Monge Type Surface with Parabola and Sinusoid Curves by Variational-Difference Method
}

\author{
Vyacheslav Ivanov and Marina Rynkovskaya \\ Peoples' Friendship University of Russia, Engineering Department, 117198, Miklukho-Maklaya Str., 6, Moscow, Russia
}

\begin{abstract}
The paper is about the stress-strain state of the thin shell in the form of Monge surface with parabola generatrix and sinusoid guide. Coordinate system of the Monge surface is a system of coordinate lines of the principal curvatures of the surface. The variational-difference method is used for analysis. Variational-difference method allows using the geometric characteristics of the middle surface of the shell, which is important in the calculation of shells of complex shape. In the finite element method, which is often used in the shells of complex shape analysis, the equation of the middle surface of the shell is used only for finite element mesh.
\end{abstract}

\section{Introduction}

The Monge surface is formed by the movement of a plane fixed generatrix curve which is moving in the orthogonal plane of the directrix curve, with one point of the generatrix curve is linked to the guide curve. If the guide curve is plane, the generatrix curve doesn't rotate in the orthogonal plane of the guide curve [1-6].

In paper, the variational-difference method (VDM) $[2$, $4,7-13]$ is used for analysis of the stress-strain state of the shell. The variational-difference method is based on the Lagrange principle, the principle of minimum total potential energy [14-22]. The Lagrange principle can be performed as the following: the total potential energy reaches the absolute minimum for the displacements (among all possible displacements) which satisfies the given boundary conditions and the equilibrium equations.

When analysing shells by the VDM the middle surface of the shell is covered with a mesh of constant or variable density. The grid lines coincide with the coordinate lines of principal curvatures. The derivatives of the displacements in the strain vector are replaced with finite-difference relations. In this case the total potential energy functional becomes a function of strain nodal displacements. Then, in order to minimize the total potential energy the Ritz-Timoshenko procedure is used. Solution of the system of equations gives the nodal displacements. Using the differential equations again the tangential and bending forces can be obtained.

At the Department of Strength of Materials and Structures of the Engineering Faculty of Russian Peoples' Friendship University, a software package for the variational-difference analysis of the shells of the noncanonical form is developed [2, 4, 23, 24].

The complex includes a library of curves, which allows forming various thin-walled shells and calculating all geometric characteristics which are used in the equations of the shells.

\section{Methods}

\subsection{Design of the shell}

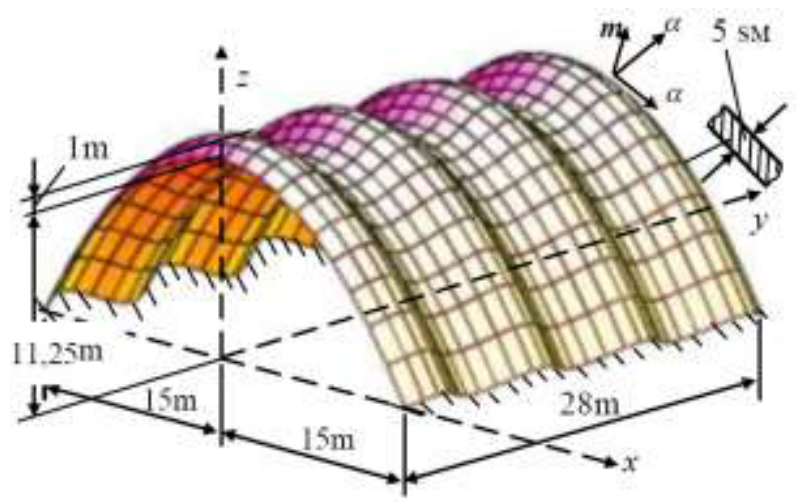

Figure 1. The wavy shell with parabola-sinusoid curves.

The guide curve is a parabola $\left(z=a x^{2}+b ; \mathrm{a}=-0,05\right.$; $\mathrm{m}-1 ; b=11,5 \mathrm{~m} ;-15 \leq \mathrm{x} \leq 15(\mathrm{~m}))$ at vertical plane and generatrix curve is a sinusoid with 7 half-waves $(z=c \sin (\pi y / d)=c \sin (p \pi y / L) ; c=1 \mathrm{~m} ; L=28 \mathrm{~m}-$ the length of the shell; $d=L / p$ - the length of a halfwave; $p=7$ - the number of the half-waves of the shell.

If the number of the half-waves is odd the shell haves a plane of symmetry when $y=L / 2$. The design of the shell is shown at figure 1 .

At the cross-sections $x=-15 ; x=15$ the sides of the shell are fixed; the sides $y=0, y=L$ are free.

The boundary conditions: 
$x= \pm 15 \mathrm{M}-u_{1}=u_{2}=u_{3}=; \partial u_{3} / \partial \alpha_{1}=0$

$y=0, \quad y=c-N 2=M 2=S=H=0$.

$\alpha_{1}, \alpha_{2}-$ the coordinates of the middle surface of the shell;

$u_{1}, u_{2}-$ the tangential displacement, $u_{3}-$ normal displacement; $N_{1}, N_{2}, S$ - tangential forces; $M_{1}, M_{2}, H-$ bending forces.

Since the shell has two planes of symmetry, the analysis was performed for the shell sector

$$
-15 \leq x \leq 0,0 \leq y \leq L / 2=14 \text {. }
$$

At the plane of the symmetry the following conditions were realized:

$u_{1}=0 ; \partial u_{3} / \partial \alpha_{1}=0$ when $\alpha_{l}=0$;

$u_{2}=0 ; \partial u_{3} / \partial \alpha_{2}=0$ when $\alpha_{2}=L / 2$.

\subsection{The results and analysis}

The calculation was made with the grid of $80 \times 140$ (40 steps per one half-wave of the sinusoid). The sole weight of the shell $(\gamma=25 \mathrm{kN} / \mathrm{m} 3)$ was taken as an external load. The characteristics of the material: Young's modulus is $E=35000 \mathrm{MPa}$, Poisson's ratio is $v=0.15$.

The epures of the tangential force $N_{l}$ and bending $M_{l}$, $M_{2}$ moments are shown at the figures 2-4. The tangential forces $N_{2}$ are much less $(5-6 \%)$ then forces $N_{l}$. The relationship for forces is $N_{2}=v N_{1}$ only at the fixed edge $(x=-15)$. That is why the epure of the force $N_{2}$ is not presented here.
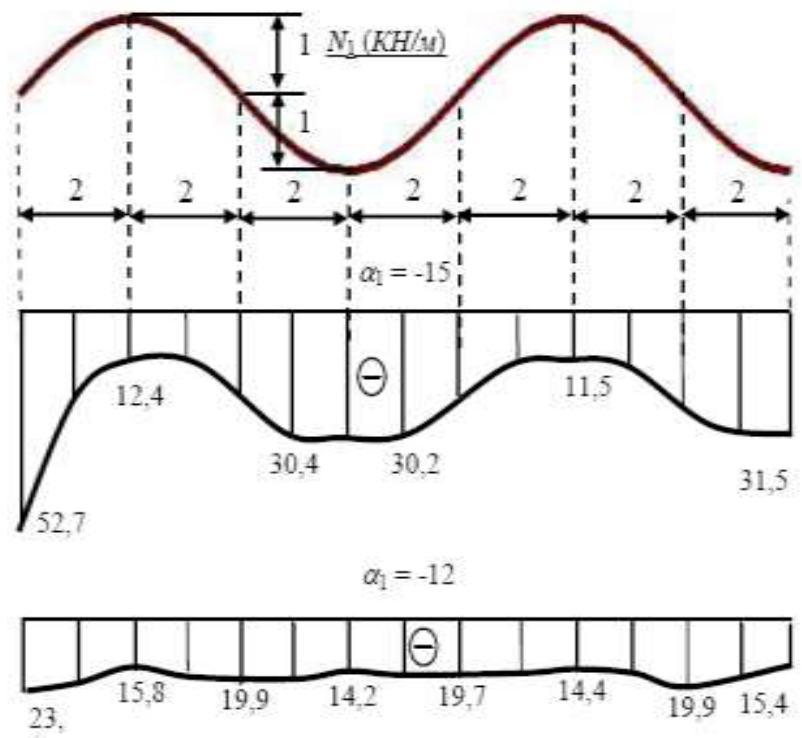

6
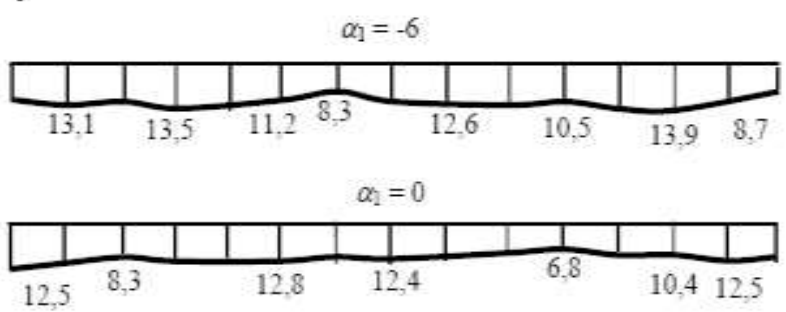

Figure 2. Normal tangential forces.

It is shown on the given graphics that the biggest compressing normal forces occur at the supporting crosssection $x=-15$. Those stresses decrease 2-3 times in the middle zone. It may be also seen that the internal forces have a wavy character in longitudinal direction.

The big bending moments $M_{1}$ occur only in the supporting zone which is caused by the boundary effect.

The maximal bending moments $M_{2}$ can be seen at $1 / 3$ of the bottom part of the shell while they decrease in 2-4 times in the middle section of the shell.

The comparison of internal forces of the first three waves of 9 waves shell with internal forces in the same waves of shell with 7 waves shows that they vary slightly.

So there may be made a conclusion: for the equal (in longitudinal direction) load the first 3.5 waves (so as three last) of the many waves (7, 9 and more waves) shell may be analyzed for 3.5 waves with real boundary conditions on the left boundary and conditions of symmetry on the right side (3.5 waves).

As far as the middle waves (the forth and next) of the many-waved shell are concerned, all of them may be analyzed as 1 wave shell with the boundary conditions coinciding with conditions of the symmetry:

$$
\begin{array}{lll}
u_{2}=0 ; & \partial u_{3} / \partial \alpha_{2}=0 & \text { when } \alpha 2=0 ; \\
u_{2}=0 ; & \partial u_{3} / \partial \alpha_{2}=0 & \text { when } \alpha 2=\mathrm{d},
\end{array}
$$

where $d$ is a length of a half-wave of the shell.
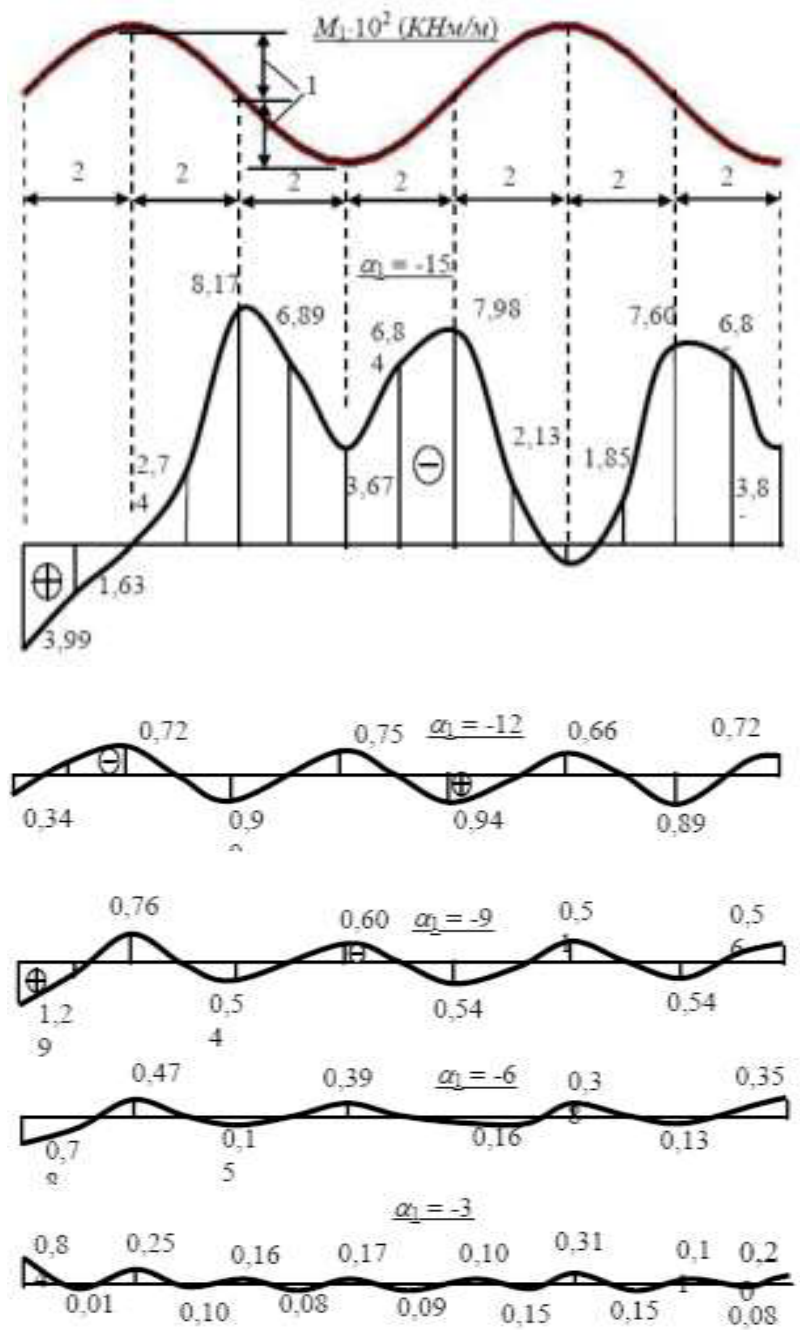

Figure 3. Bending moments $M 1$.

It is possible to analyze a half part of the half-waved section, as it has a plane of symmetry. 

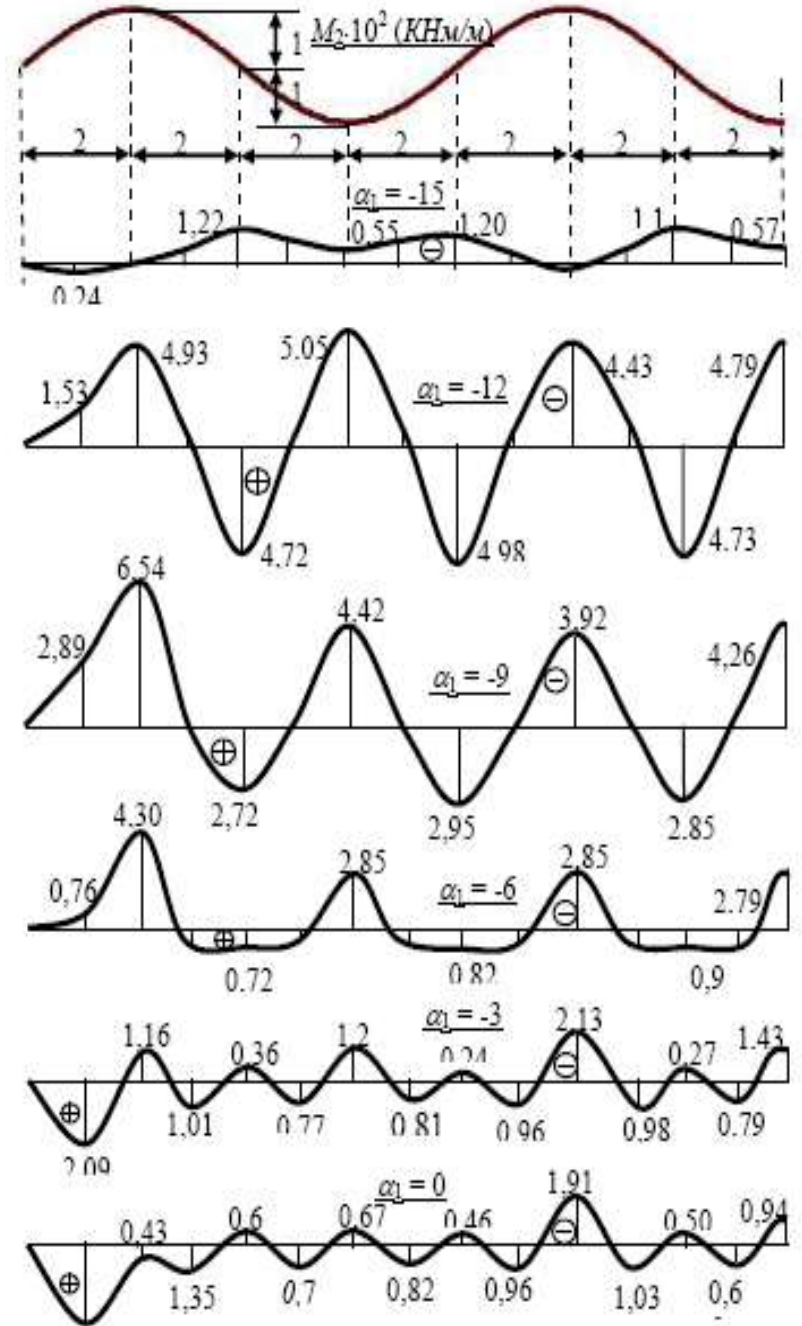

32

Figure 4. Bending moments M2

At Figure 5, the sections of the shell which may be used for analysis of the middle waves of the many-waved shell are shown.

At the Tables 1, 2, the results of calculation of the middle wave of the shell with 9 half-waves and one section (Figure 5, a) are shown.

The analysis of the middle section was made on the grid of $80 \times 80$ steps and the $1 / 4$ part of 9 half-waved surface with the grid of $80 \times 180$. This gives the equal precision of the results of calculation of both structures as they have equal steps of the grid. Generally, the difference in the strains of the regarded parts of the structure does not exceed 1-3\%. Only the longitudinal strains $\sigma_{N 2}$ at some parts differ more. But those stresses are much less than the stresses $\sigma_{N 2}$ and this will have no effect on the strength of the structure.

The calculations of section which is presented at Figure $5, b$ shows mostly the same results as for sections at Figure 5, $a$.

The comparison of the stress-strain state of the section from Figure 5, a with stress-strain state of the middle (4, 5) wave of shell with 9 half-waves shows the similar results.
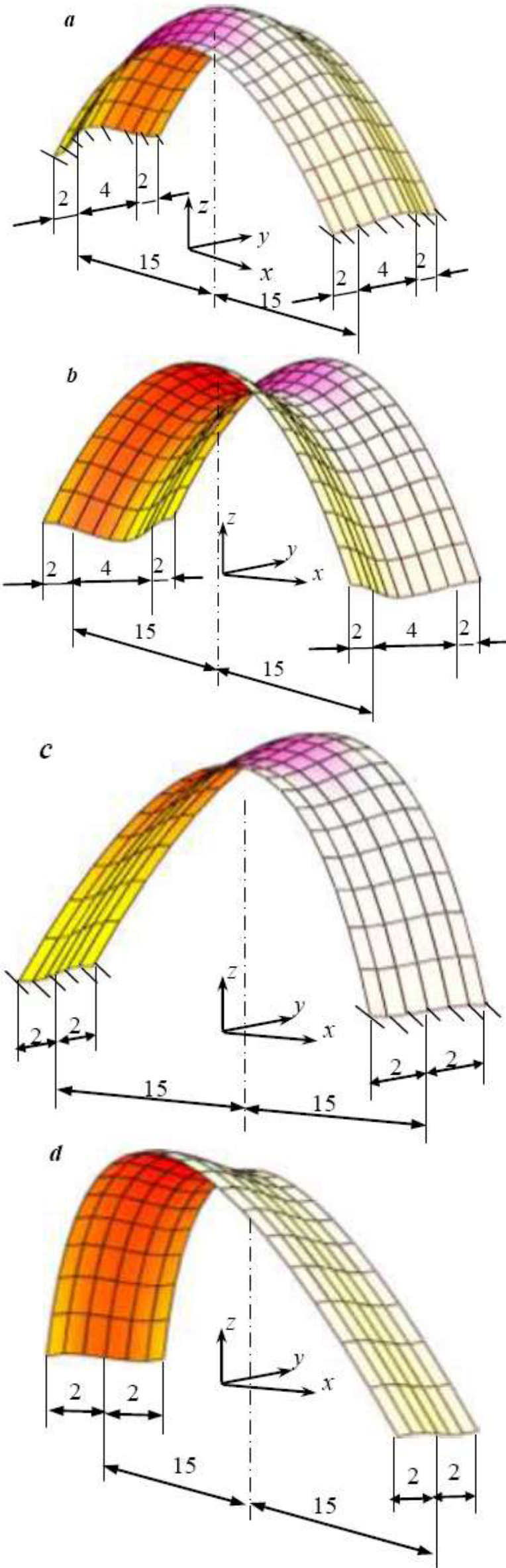

Figure 5. Middle sections of the wavy shell. 
Table 1. Results of calculation of the middle wave of the shell.

\begin{tabular}{|c|c|c|c|c|}
\hline \multirow{2}{*}{$\begin{array}{l}\text { Number of } \\
\text { half-waves }\end{array}$} & \multicolumn{2}{|c|}{$\sigma_{N 1}(\mathrm{kPA})$} & \multicolumn{2}{|c|}{$\sigma_{N 2}(\mathrm{kPA})$} \\
\hline & 9 & отс. & 9 & отс. \\
\hline$\alpha_{1}(\mathrm{~m})$ & \multicolumn{4}{|c|}{$\alpha_{2}=0 \mathrm{~m}$} \\
\hline-15 & -230 & -237 & $-34,2$ & $-35,5$ \\
\hline-12 & -287 & -290 & $-11,1$ & $-13,7$ \\
\hline-9 & -272 & -272 & $-11,2$ & $-0,66$ \\
\hline-6 & -211 & -211 & $-13,0$ & $-8,62$ \\
\hline-3 & -159 & -159 & $-16,0$ & $-10,6$ \\
\hline 0 & -138 & -139 & $-17,7$ & $-10,5$ \\
\hline$\alpha_{1}(\mathrm{~m})$ & \multicolumn{4}{|c|}{$\alpha_{2}=2 \mathrm{~m}$} \\
\hline-15 & -432 & -433 & $-64,2$ & $-65,0$ \\
\hline-12 & -399 & -399 & $-3,33$ & $-3,08$ \\
\hline-9 & -340 & -340 & 0,60 & 1,09 \\
\hline-6 & -277 & -277 & $-1,36$ & $-0,63$ \\
\hline-3 & -227 & -227 & $-7,54$ & $-6,50$ \\
\hline 0 & -207 & -207 & $-11,5$ & $-10,3$ \\
\hline$\alpha_{1}(\mathrm{~m})$ & \multicolumn{4}{|c|}{$\alpha_{2}=4 \mathrm{~m}$} \\
\hline-15 & -630 & -629 & $-94,5$ & $-94,4$ \\
\hline-12 & -308 & -306 & 10,2 & 10,5 \\
\hline-9 & -174 & -171 & 17,3 & 17,5 \\
\hline-6 & -168 & -165 & 15,3 & 15,6 \\
\hline-3 & -213 & -209 & 2,91 & 3,49 \\
\hline 0 & -238 & -234 & $-5,88$ & $-5,16$ \\
\hline$\alpha_{1}(\mathrm{~m})$ & \multicolumn{4}{|c|}{$\alpha_{2}=6 \mathrm{~m}$} \\
\hline-15 & -434 & -433 & $-65,1$ & $-65,0$ \\
\hline-12 & -400 & -399 & $-31,2$ & $-30,8$ \\
\hline-9 & -340 & -340 & 0,88 & 1,29 \\
\hline-6 & -277 & -277 & $-1,15$ & $-0,63$ \\
\hline-3 & -227 & -227 & $-7,36$ & $-6,50$ \\
\hline 0 & -207 & -207 & $-11,3$ & $-10,3$ \\
\hline$\alpha_{1}(\mathrm{~m})$ & \multicolumn{4}{|c|}{$\alpha_{2}=8 \mathrm{~m}$} \\
\hline-15 & -240 & -237 & $-35,9$ & $-35,5$ \\
\hline-12 & -290 & -290 & $-13,7$ & $-13,7$ \\
\hline-9 & -271 & -272 & 0,48 & 0,66 \\
\hline-6 & -209 & -211 & 8,23 & 8,62 \\
\hline-3 & -156 & -159 & 10,0 & 10,6 \\
\hline 0 & -135 & -139 & 9,81 & 10,0 \\
\hline
\end{tabular}

Table 2. Results of calculation of the middle wave of the shell.

\begin{tabular}{|c|c|c|c|c|}
\hline \multirow{2}{*}{$\begin{array}{l}\text { Number of } \\
\text { half-waves }\end{array}$} & \multicolumn{2}{|c|}{$\sigma_{M 1}(\mathrm{kPA})$} & \multicolumn{2}{|c|}{$\sigma_{M 2}(\mathrm{kPA})$} \\
\hline & 9 & отс. & 9 & отс. \\
\hline$\alpha_{1}(\mathrm{~m})$ & \multicolumn{4}{|c|}{$\alpha_{2}=0 \mathrm{~m}$} \\
\hline-15 & 9,81 & 10,9 & 1,48 & 1,63 \\
\hline-12 & $-15,8$ & $-15,6$ & -106 & -106 \\
\hline-9 & $-12,3$ & $-12,3$ & $-94,2$ & $-94,7$ \\
\hline-6 & $-9,00$ & $-9,11$ & $-68,2$ & $-69,6$ \\
\hline-3 & $-7,49$ & $-7,52$ & $-50,9$ & $-51,1$ \\
\hline 0 & $-7,16$ & $-7,18$ & $-45,6$ & $-45,0$ \\
\hline$\alpha_{1}(\mathrm{~m})$ & \multicolumn{4}{|c|}{$\alpha_{2}=2 \mathrm{~m}$} \\
\hline-15 & -183 & -182 & $-27,4$ & $-27,3$ \\
\hline-12 & 21,3 & 21,2 & 114 & 113 \\
\hline-9 & 12,9 & 12,9 & 68,2 & 68,6 \\
\hline-6 & 3,07 & 3,12 & 19,6 & 19,8 \\
\hline-3 & $-2,70$ & $-2,76$ & $-6,28$ & $-6,16$ \\
\hline 0 & $-3,75$ & $-3,90$ & $-11,9$ & $-11,9$ \\
\hline$\alpha_{1}(\mathrm{~m})$ & \multicolumn{4}{|c|}{$\alpha_{2}=4 \mathrm{~m}$} \\
\hline-15 & $-91,3$ & $-91,4$ & $-13,7$ & $-13,7$ \\
\hline-12 & $-17,2$ & $-17,2$ & -115 & -115 \\
\hline-9 & $-13,4$ & $-13,4$ & -102 & -102 \\
\hline-6 & $-8,54$ & $-8,61$ & $-67,0$ & $-67,5$ \\
\hline-3 & $-4,80$ & $-4,91$ & $-34,4$ & $-34,9$ \\
\hline 0 & $-4,03$ & $-4,16$ & $-22,8$ & $-23,3$ \\
\hline$\alpha_{1}(\mathrm{~m})$ & \multicolumn{4}{|c|}{$\alpha_{2}=6 \mathrm{~m}$} \\
\hline-15 & -181 & -182 & $-27,1$ & $-27,3$ \\
\hline-12 & 21,0 & 21,2 & 112 & 113 \\
\hline-9 & 12,9 & 12,9 & 62,8 & 68,6 \\
\hline-6 & 3,19 & 3,12 & 19,8 & 19,8 \\
\hline-3 & $-2,67$ & $-2,76$ & $-6,15$ & $-6,16$ \\
\hline 0 & $-3,82$ & $-3,90$ & $-11,9$ & $-11,9$ \\
\hline$\alpha_{1}(\mathrm{~m})$ & \multicolumn{4}{|c|}{$\alpha_{2}=8 \mathrm{~m}$} \\
\hline-15 & 11,5 & 10,9 & 1,73 & 1,63 \\
\hline-12 & $-15,2$ & $-15,6$ & -104 & -104 \\
\hline-9 & $-12,3$ & $-12,3$ & $-94,4$ & $-94,7$ \\
\hline-6 & $-9,15$ & $-9,11$ & $-69,8$ & $-69,6$ \\
\hline-3 & $-7,59$ & $-7,52$ & $-51,7$ & $-51,1$ \\
\hline 0 & $-7,26$ & $-7,18$ & $-45,7$ & $-45,0$ \\
\hline
\end{tabular}

\section{Conclusion}

The analysed waved surface may be used for roofing of the buildings such as the trading, exhibition or sports 
centres. The variational-difference method which was used for analysing of stress-strain state of the structure allows taking into account the possibilities of the geometry of the shell. The calculation of the construction was made with different mesh density in order to receive the necessary accuracy of the result.

In paper, there are the results which were obtained for the grid of $80 \times 140$. Such approach gives the difference in results less than $5 \%$.

The many wave shells with different boundary conditions on the left $\left(\alpha_{2}=0\right)$ and right $\left(\alpha_{2}=L\right)$ sides may be analyzed separately: by left and right sections with three of half waves with their boundary conditions and middle waves as well.

The boundary conditions on the left $(x=0)$ and the right ( $x=b, b-$ the width of the shell) longitudinal sides of the shell may differ. In this case, the symmetry on coordinate $x$ is not used.

If the load is not constant in the longitudinal direction (in direction of $y$ ) then it is necessary to analyze the whole construction.

\section{References}

1. S.N. Krivoshapko, V.N. Ivanov. Encyclopedia of Analytical Surfaces. Springer International Publishing Switzerland, 752 p. (2015)

2. V.N Ivanov, S.N. Krivoshapko. Analytical methods of analyses of shells of non canonic form. Moscow, RUDN, 542 p. (2010)

3. V.N Ivanov, M. Rizvan. Geometry of Monge surfaces and construction of the shell. Structural mechanics of $\mathrm{s}$ and buildings. construction: Collection of science works, Vol. 11, ACB, p. 27-36. (2002)

4. V.N Ivanov, Younis Nasr. Analyses of the shells of complex geometry by variation differential difference method. Collection of science works, Vol. 11, ACB, p. 25-34. (2000)

5. B. Bulca, K. Arslan, "Surfaces Given with the Monge Patch in E4E4", Журн. матем. физ., анал., геом., 9:4, p. 435-447. (2013)

6. Romain MESNIL, Yann SANTERRE, Cyril DOUTHE, Olivier BAVEREL, Bruno LEGER. Generating high node congruence in freeform structures with Monge's Surfaces. Proceedings of the International Association for Shell and Spatial Structures (IASS), (2015)

7. Ivanov V.N., Gil-oulbe Mathieu. Some Aspects of the Geometry of Surfaces with a System of Flat Coordinate Lines, International Journal of Soft Computing and Engineering (IJSCE), p. 77-82 (2014)

8. R. Lagu, A variational finite-difference method for analyzing channel waveguides with arbitrary index profiles, IEEE Journal of Quantum Electronics, Vol. 22, Iss. 6, pp. 968-976 (1986)

9. G.D. Smit, Numerical Solution of Partial Differential Equations by Finite Difference Methods, 2nd edit., Oxford Applied Mathematics and Computing Science Series, UK, 350p. (1986)
10. S. G. Mikhlin, Variational-difference approximation, Journal of Soviet Mathematics, Vol. 10, Iss. 5, pp. 661-787 (1978)

11. A.R. Mitchell, D.F. Griffiths, The finite difference method in partial differential equations, Wiley, 284p. (1980)11. Curant R., Variational methods for the solution of problems of equilibrium and vibrations, Bulletin of the American Mathetics Society, Vol.49, pp. 1-23 (1943)

12. V. A. Maksimyuk, E. A. Storozhuk I. S. Chernyshenko. Variational finite-difference methods in linear and nonlinear problems of the deformation of metallic and composite shells (review). International Applied Mechanics, Vol. 48, Iss. 6, pp 613-687 (2012).

13. Singh J.P., Dey S.S. Variational finite difference method for free vibration of sector plates. Journal of Sound and Vibration, Vol. 136, Iss. 1, p. 91-104 (1990)

14. Curant R., Variational methods for the solution of problems of equilibrium and vibrations, Bulletin of the American Mathetics Society, Vol.49, pp. 1-23 (1943)

15. Reddy J. N., Energy Principles and Variational Methods in Applied Mechanics, John Willy and Co, Inc. New Jersey, USA, 542p. (2002)

16. R. Andujar Moreno, J._Roset, V. Kilar, Variational Mechanics and Stochastic Methods Applied to Structural Design, 173p. (2014).

17. Aginam C. H., Chidolue C. A. and Ezeagu C. A., Application of direct variational method in the analysis of isotropic thin rectangular plates, ARPN Journal of Engineering and Applied Sciences, Vol. 7, N9, pp. 1128-1138 (2012)

18. C. Lanczos, The variational principles of mechanics, University of Toronto Press, Canada, 418p. (1970)

19. J.H. Argyris, Energy theorems and structural analysis, Butterworths Scientific publications, London, UK, 85p. (1960)

20. L. Lapidus, G.F. Pinder, Numerical solution of partial differential equations in science and engineering, Wiley-Interscience, New York, 677p. (1982)

21. W. Wunderlich, W. Pilkey, Mechanics of structures. Variational and computational methods, CRC Press, pp. 852-877 (2002)

22. Ivanov V.N. Variation priciples and methods od analyses of the problems of theory of elastisityt. Moscow, RUDN, 2001, $176 \mathrm{p}$.

23. Ivanov V.N. The base of the finite elements method and the varation-difference method. Moscow, RUDN, 2008, $170 \mathrm{p}$.

24. Ivanov V.N., Kushnarenko I.V. The VariationalDifference Method for the Analisis of the Shells with Complex Geometry// International Association for Shell and Spatial Structures Proceedings of the IASS 2013 Symposium "Beyond the Limits of Man", 6 p. (2013) 